\title{
Legg-Calvé-Perthes hastalığında MR görüntüleme
}

\author{
MR imaging in Legg-Calvé-Perthes disease
}

\author{
Alptuğ Özen ${ }^{1}$, Hatice Tuba Sanal' ${ }^{1}$ Cemil Yıldız² \\ ${ }^{1}$ Sağlık Bilimleri Üniversitesi, Gülhane Tıp Fakültesi, Radyoloji Anabilim Dalı \\ ${ }^{2}$ Sağlık Bilimleri Üniversitesi, Gülhane Tıp Fakültesi, Ortopedi ve Travmatoloji Anabilim Dalı
}

\begin{abstract}
Legg-Calvé-Perthes hastalığı (LCP) nedeni bilinmeyen çocukluk çağı femur başı osteonekrozudur. ${ }^{[1]}$ Manyetik rezonans (MR) görüntüleme, LCP'nin erken tanısı, evresini ortaya koymada ve tedaviyi değerlendirmede kullanılabilen bir tekniktir. MR bulguları, hastalığın farklı evrelerine göre değişkenlik gösterebilmektedir. Bu yazıda, MR görüntülemenin LCP hastalığı tanısındaki yerinden ve bulgularından bahsedilecektir.
\end{abstract}

Anahtar sözcükler: Legg-Calvé-Perthes; MR görüntüleme; diffüzyon ağırıklı görüntüleme; perfüzyon görüntüleme
Legg-Calvé-Perthes (LCP) disease refers to the osteonecrosis of the femoral head of childhood with unknown etiology [1]. Magnetic resonance (MR) imaging is a technique that can be used for early diagnosing, staging and evaluating the treatment. MR imaging findings may display variations according to the different stages of the disease. In this review, the role of MR imaging along with the findings on images in the evaluation of LCP disease will be displayed.

Key words: Legg-Calvé-Perthes; MR imaging; diffusion weighted imaging; perfusion imaging

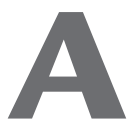

vasküler nekroz, epifiz ya da subartiküler kemik dokuyu perfüze eden kan akımının azalması ya da tamamen kesilmesi sonucu ortaya çıkan ve sık görülen bir tablodur. Legg-CalvéPerthes (LCP) hastalığı ya da bilinen diğer ismi ile osteokondritis koksa juvenilis; gelişmekte olan femur proksimal epifizinin nedeni bilinmeyen avasküler nekrozu ve sonrasında ortaya çıkan, femur başının dışa dislokasyonu ile karakterize, kendini sınırlayan bir tablodur. ${ }^{[2,3]}$ Manyetik rezonans (MR) görüntüleme ile radyografik bulguların görünür olmasından önce tanı konabilir. Femur başının şekli, pozisyonu, boyutu, medüller yapısına dair ipuçları ve çevre yumuşak dokuların değerlendirilmesinde MR görüntüleme tercih edilir. Yine, MR görüntüleme ile prognozda önemli olan kıkırdak tutulumu ve eklem bütünlüğü ortaya konabilir. Avasküler evrede T1-A görüntülerinde femur başı epifizinin yağ intensitesinde kayıp, revaskülarizasyon evresinde i.v. kontrast sonrası MR görüntülerinde parlama, eklemde effüzyon, kıkırdakta hipertrofi, görülebilen diğer bulgulardır.

\section{MANYETIK REZONANS GÖRÜNTÜLEME}

Osteonekrozun saptanmasında en duyarlı ve özgün görüntüleme yöntemi MR'dir. ${ }^{[1]}$ Olguların erken tanısı, evrelenmesi ve eşlik eden komplikasyonların değerlendirilmesinde yararlı bir yöntemdir. ${ }^{[4]}$ Bazı MR görüntüleme bulguları prognoz açısından değerli bilgiler verir. Ayrıca, hasta popülasyonun yaşı göz önüne alındığında, iyonizan radyasyon içermemesi yöntemin bir diğer üstünlüğüdür.

$\mathrm{Bu}$ popülasyonda, i.v. kontrastla yapılan MR $(+K M R)$ 'nin rolünden bahseden çalışmalar vardır. Substraksiyon tekniğinin kullanıldığı $+K M R$ görüntüleme yapılan bir çalışmada, hastalığın erken evresinde hipoperfüzyon alanının daha iyi ortaya konduğu ifade edilmiştir. ${ }^{[3]}$ Dinamik olarak yapılan $+K M R$ ile, diğer MR bulguları ortaya çıkmadan önce hastalığın tanınabileceğini ifade eden çalışmalar da vardır. ${ }^{[3]}$ Bu bağlamda, MR'nin bir diğer üstünlüğü, karşı kalçada asemptomatik osteonekrozun saptanmasındaki yararlılığıdır.

Son yıllarda, diffüzyon sekansları, görünür diffüzyon katsayısı (apparent diffusion coefficient -ADC)

- İletişim adresi: Dr. Cemil Yıldız, SBU Gülhane Tıp Fakültesi Ortopedi ve Travmatoloji Anabilim Dalı, Etlik, Ankara Tel: 0312 - 3045501 e-posta: cyorto@yahoo.com

- Geliş tarihi: 20 Șubat 2017 Kabul tarihi: 20 Șubat 2017 
haritalanması ve T2 haritalama gibi yöntemlerin katkısından da bahsedilmektedir. ${ }^{[3]}$

\section{Hasta Hazırlığı ve Görüntüleme Protokolü}

Hazırlık aşamasında, olguların böbrek fonksiyon testlerinin yapılması ve glomerüler filtrasyon oranının bilinmesi gerekir. Nefrojenik sistemik fibrozis, böbrek fonksiyonu bozuk olan olgularda gadolinyum bazlı kontrast madde kullanımı sonrasında gelişen ve hemen tüm organları ilgilendirebilecek fibrozis ile karakterize katastrofik bir tablodur. LCP nedeniyle değerlendirilen popülasyonun pediatrik yaş grubu olması nedeniyle, görüntülemede hareketsizliğin sağlanması için anestezi gerekebilir. Sankar ve arkadaşları ${ }^{[5]}$ perfüzyon MR tetkiki yapılmış LCP olgularını değerlendirdikleri çalışmalarında, olguların \%16'sının genel anestezi gereksinimi olduğunu, \%31'inin sedasyon ile görüntülendiğini, \%41'inde ise hastaların video gözlükleri ile hareketsiz durabildiklerini bildirmişlerdir. Aynı çalışmada, anestezi (ort. 7,7 72,3 yaş) ya da sedasyon (ort. $7,2 \pm 2,4$ yaş) gerektiren olguların yaşlarının, herhangi bir girişim gerekmeyen olgulara (ort. 10,2 $\pm 2,3$ yaş) göre anlamlı derecede küçük olduğu belirtilmiştir.

MR görüntüleme supin pozisyonda gerçekleştirilmekte olup, vücut sarmalı (koil) ya da yüzey sarmalları kullanılmaktadır. Yüzey sarmalları, artmış sinyal/ gürültü oranı ve daha yüksek uzaysal çözünürlük sağlaması nedeniyle tercih edilmektedir. ${ }^{[4]}$ Görüntüleme, koronal ve sagittal düzlemlerde çeşitli $M R$ sekansları (T1-A spin eko (SE) ya da gradient eko (SPGR), T2-A fast spin eko (FSE) ve proton dansite (PD-FSE) kullanılarak yapılmaktadır. Bu sekansların her biri için yağ baskılı ya da yağ baskısız görüntüleme seçenekleri mevcuttur. Femur başı kollapsının değerlendirilmesinde, sagittal görüntülerin koronal plana göre daha doğru bilgi verdiği gösterilmiştir. ${ }^{[6]}$ Aynı çalışmada, olguların \%26'sında femur başı kollapsının sadece sagittal görüntülerde görülebildiği belirtilmektedir. LCP olgularında, MR'de kontrast madde kullanımından daha önce bahsedilmiştir. Kontrast madde enjeksiyonu sonrasında alınan yağ baskılı T1-A SE ya da SPGR görüntüler, proksimal femoral epifiz vaskülaritesinin değerlendirilmesinde önemlidir. ${ }^{[7]}$

İyileşme fazında ortaya çıkan vaskülarizasyon artışı, vazodilatasyon ve artmış kapiller permeabiliteye bağlı olarak, $+K M R$ görüntülerinde artmış kontrastlanma ortaya çıkar. ${ }^{[8]}$

MR, iyileşmiş LCP olgularında asetabular kıkırdaktaki bozuklukların \%47'sini, labral anormalliklerin ise \%75'ini ortaya koymaktadır. ${ }^{[9]}$

LCP hastalığının tanısında yukarıda bahsi geçen konvansiyonel sekanslara ek olarak kullanılan ileri MR teknikleri, hastalığın tanısı, evrelendirilmesi ve prognozun ön görülmesinde yararlı bilgiler verebilir.

\section{İleri MR Görüntüleme Teknikleri}

\section{Diffüzyon ağırlıklı görüntüleme (DAG)}

Güncel radyoloji pratiğinde en yaygın olarak "akut serebral iskemi" tanısında kullanılmaktadır. Bu yöntemde görüntü kontrastı, suyun moleküler hareketi (Brownian hareket) temeline dayanır. Dokular, suyun diffüzyon hızlarına bakılarak karakterize edilmeye çalışılır. Femur başındaki iskemik değişikliği, suyun mikroskopik hareketliliğini değerlendirerek tespit edebilmektedir. Bu değerlendirme, görsel olarak kalitatif şekilde yapılabileceği gibi, görünür diffüzyon katsayısı (ADC) değerleri ölçülerek sayısal veriler de elde edilebilir.

Eklemin prognozunu belirlemek ciddi bir zorluktur. Erken dönemde önleyici tedaviden yarar görebilecek olguların seçiminde DAG ek bilgi verebilir. LCP olgularında, lateral epifizyel arterler ile oluşan erken beslenmenin, yavaş transfizyel neovaskülarizasyona göre daha iyi prognoza sahip olduğu bildirilmiştir. ${ }^{[10]}$ DAG'nin, femur başı epifizi iskemisinin erken tespitinde oldukça duyarlı bir yöntem olduğu, birçok hayvan çalışması ile ortaya konulmuştur. ${ }^{[11]}$ İskemik olayın hemen sonrasında diffüzyon kısıtlaması görülse de, saatler ya da günler içerisinde hem diffüzyon hem de ADC değerlerinde artış görüldüğü ifade edilmiştir. Baunin ve arkadaşları[ ${ }^{[12]}$ yaptıkları çalışmada, erken dönemde DAG ile görüntülenen LCP olgularında, femur başı epifizi ve metafizinde ADC değerlerinde kontrol grubuna göre artış olduğunu saptamışlardır. Aynı çalışmada, metafizyel ADC değerlerinde artış ile dinamik $+K M R$ 'de lateral pillar kesiminde kontrastlanma yokluğu, transfizyel neovaskülarizasyon ve fiziyel anomaliler arasında korelasyon olduğu gösterilmiştir. Boutault ve arkadaşları ${ }^{[13]}$ LCP nedeniyle takipli olan 27 olgu ile yaptıkları çalışmada, patolojik femur boynundan ölçülen ADC değerlerinin sağlıklı tarafa göre anlamlı olarak yüksek olduğunu göstermişlerdir. Elde edilen ADC oranlarının Catterall sınıflamasına benzer biçimde anlamlı düzeyde artış gösterdiği ve takip incelemesi olan olgularda ADC oranlarının zamanla değişim göstermediği de, aynı çalışmada ortaya konulan diğer bulgulardır. DAG'nin non-invaziv bir yöntem olması ve kontrast madde kullanılmaması önemli avantajlarıdır. Ayrıca, EPI (echoplanar imaging) sekansı gibi çok hızlı görüntüleme tekniklerinin kullanılması, hareket artefaktlarını en aza indirmekte ve genel anesteziye duyulan ihtiyacı büyük ölçüde ortadan kaldırmaktadır.

\section{Perfüzyon MR}

Herring ve arkadaşları ${ }^{[14]}$ LCP olgularında fragmantasyon evresinde, femur başı epifizinin lateral 1/3'ünde izlenen kollapsın yaygınlığı ile klinik sonucun kuvvetli 


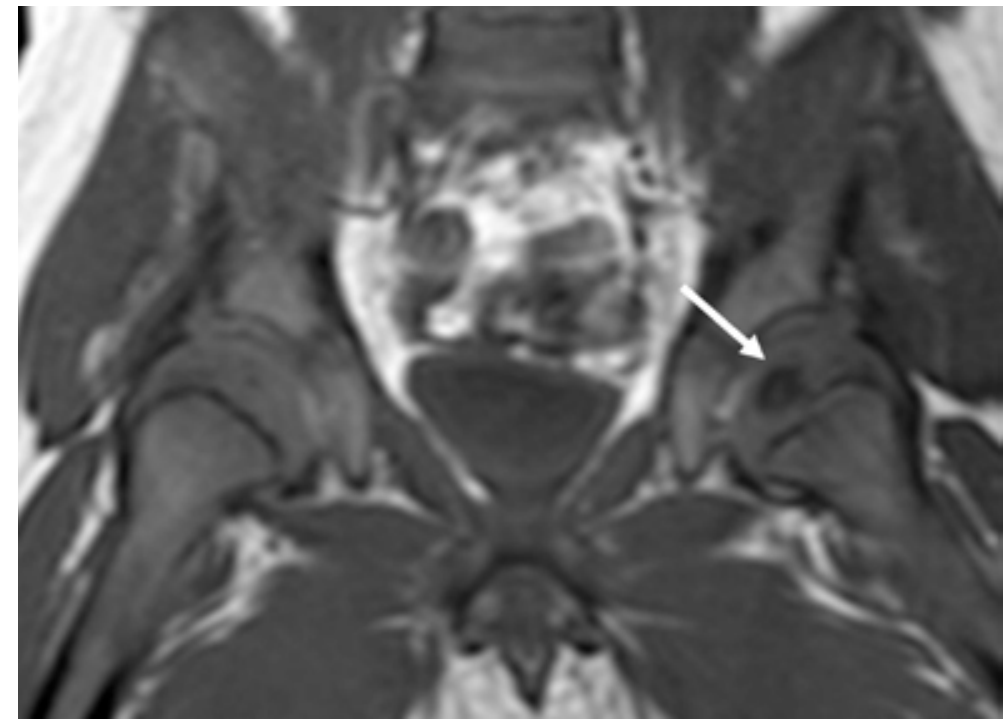

Şekil 1. İki buçuk yaşında erkek olguya ait koronal T1-A TSE görüntüde femur başı epifizinde sinyalsiz olarak izlenen ( $o k)$ nekroz ile uyumlu bir alan izlenmektedir.

korelasyonunu ortaya koymuşlardır. Ancak, fragmantasyon evresi, hastalığın başlangıç fazından itibaren yaklaşık 4-8 ay gibi bir süre sonunda ortaya çıkmakta, bu da LCP olgularında tedavide asıl hedef olan deformitenin önlenmesi ya da minimuma indirilmesi konusunda endişeler oluşturmaktadır. ${ }^{[15]}$ Kontrastsız $M R$, osteonekroz tespitinde epifizde izlenen yağ intensitesindeki değişiklikleri referans almaktadır. Bu değişikliklerin görülmesi başlangıç evresinden itibaren haftalar-aylar sürebileceğinden, kontrastsız MR'nin erken tanıda rolü kısıtlı kalır. Buna karşın, substraksiyon yöntemi kullanılarak yapılan $+K M R$ (perfüzyon $M R$ ), femur başı kanlanması hakkında bilgi vermekte ve LCP olgularında erken iskeminin tespit edilmesinde kullanılmaktadır. ${ }^{[16]}$ Kim ve arkadaşları ${ }^{[17]}$ kontrastsız MR ile kontrastlı MR tetkiki sonuçlarını karşılaştırdıkları çalışmada, kontrastlı MR'nin, LCP olgularının başlangıç evresinde femur başı nekrozunun yaygınlığını daha iyi ortaya koyduğunu göstermişlerdir. Yapılan başka bir çalışmada, LCP olgularında erken evrede femur başı epifizinde perfüzyon MR ile tespit edilen avaskülarite yaygınlığı ile, iki yıllık takip sonunda radyografik olarak izlenen femur başı deformasyonu yaygınlığının korele olduğu gösterilmiştir. ${ }^{[18]}$ Perfüzyon MR tetkikinde, konvansiyonel sekansların yanı sıra kontrast öncesi yağ baskılı T1-A sekansı ile görüntüleme yapıldıktan sonra i.v. gadolinyum $(0,2 \mathrm{ml} / \mathrm{kg}-0,5 \mathrm{mmol} / \mathrm{ml}$ - maks 20 $\mathrm{ml}$ ) enjeksiyonu yapılarak, dinamik olarak, ardışık sürelerde koronal yağ baskılı T1-A görüntüler alınır. Elde edilen kontrast sonrası görüntüler, prekontrast görüntüden çıkarılarak (substraksiyon) femur başı epifizinin kontrastlanması değerlendirilir. Sonrasında, çeşitli yazılımlar kullanılarak perfüzyon hesaplamaları yapılır. Kim ve arkadaşları yaptıkları çalışmada, LCP olgularında perfüzyon MR yardımıyla; Herring Tip A kalçalar ile Herring Tip $B$ ve $C$ kalçaların, hastalığın başlangıç fazında ayırt edilebileceğini göstermişlerdir. ${ }^{[15]}$

\section{MR Artrografi (MRA)}

MRA'da, gadolinyum içeren kontrast maddenin intraartiküler enjeksiyonu sonrasında küçük inceleme alanı kullanılarak, yağ baskılı-baskısız T1-A SE / SPGR sekanslarında değişik düzlemlerde görüntüleme yapılır. MRA, özellikle LCP'ye bağlı komplikasyonların değerlendirilmesinde yararlıdır. Eklem içi kontrast madde sayesinde, eklem yüzeyleri ile labrum ayrıntılı olarak değerlendirilebilir ve femur başı - asetabulum uyumu hakkında fikir edinilebilir. ${ }^{[4]}$

\section{LCP HASTALIĞININ EVRELERINE GÖRE MR BULGULARI}

\section{Avasküler Faz}

Hastalığın erken (avasküler-nekrotik) fazında; olgularda ağrı ve topallama gibi şikayetler sık olsa da, asemptomatik olgular da nadir değildir. Bu evrede, direkt radyografiler normal olabilir. Hastalığın en erken bulguları MR ile tespit edilebilmektedir. ${ }^{[4,19]}$ Femur proksimal epifizinin ossifik nükleusunun bir kısmı ya da tamamı nekroza gidebilir. En erken tespit edilen bulgu, femur epifizi santralinde ve subkondral kemik dokuda T1-A görüntülerde düşük sinyal intensitesi ile, yine bu lokalizasyonda ödeme bağlı olarak sıvıya duyarlı sekanslarda sinyal artışıdır (Şekil 1). Femur başının anterosuperior 

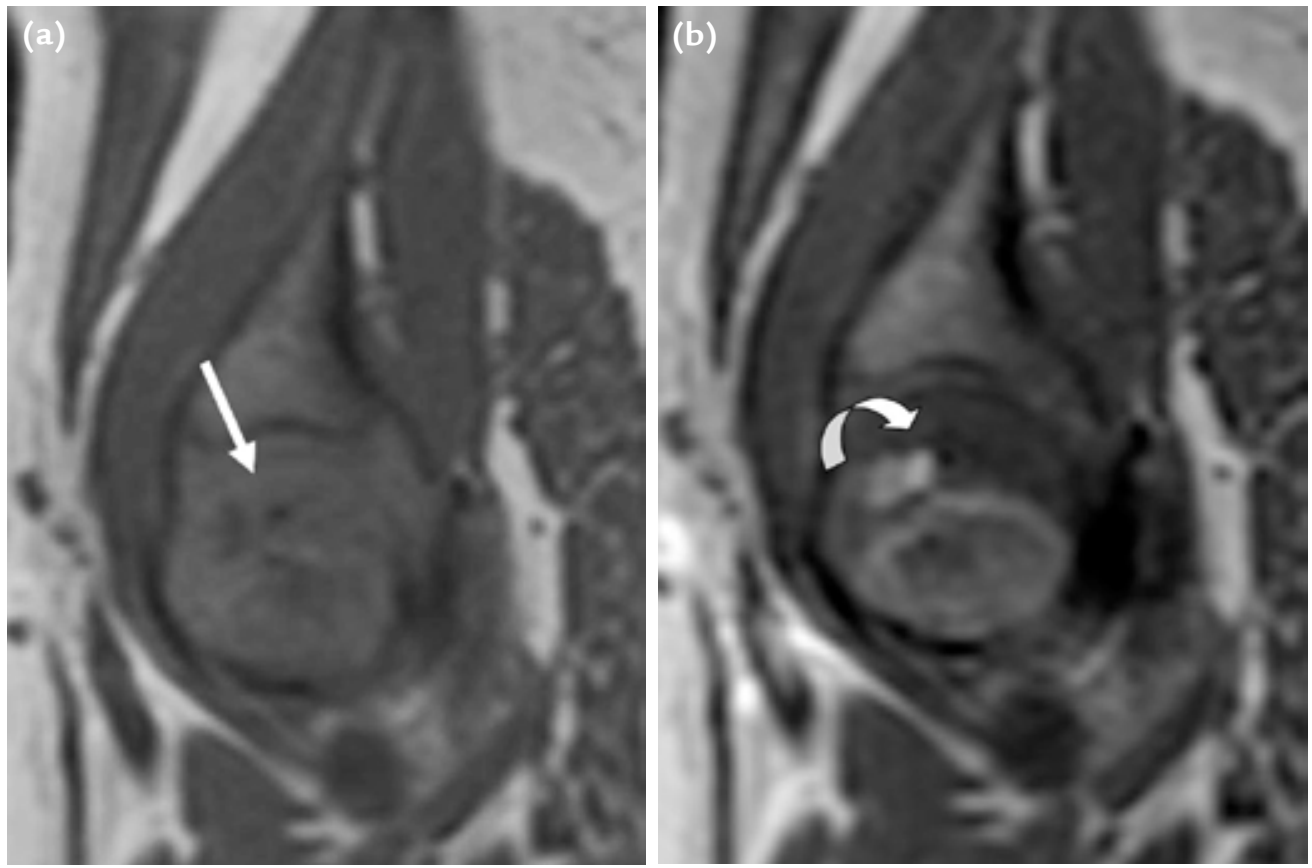

Şekil 2. a, b. Sagittal T1-A TSE (a) görüntüde femur başı epifizinde çevre dokuya göre düşük sinyalli nekroz ile uyumlu odaklar (düz ok) izlenmektedir. Post kontrast T1-A TSE (b) görüntüde bu alanda granülasyon dokusu oluşumunu ve neovaskülarizasyona işaret eden parlama (eğik ok) görülmektedir.

kesiminde, subkondral kurvilineer tarzda T2-A hiperintensitesi ve T1-A hipointensitesi gözlenebilir. Caffey işareti (kresent [hilal] işareti) olarak da bilinen bu bulgu, subkondral fraktür varlığını akla getirmektedir. Kontrast madde enjeksiyonu sonrasında, normal kalça ekleminde hızlı ve erken kontrast tutulumu gözlenirken, LCP olgularında, femur başı epifizinin bir kısmında ya da tamamında kontrastlanmayan alanlar görülür. ${ }^{[16]}$ Femur başında izlenen anormal kontrastlanma, en iyi kontrast madde enjeksiyonu sonrasında ikinci dakikada alınan substrakte görüntüde ortaya konulur. ${ }^{[4]}$ Femur başı tutulumu tipik olarak asimetrik olup, anterior kesim en erken ve en belirgin olarak tutulan bölümdür. ${ }^{[6]}$ Femur başını çevreleyen kıkırdak doku, kalınlığı artmış ve anormal sinyal özellikleri ile görülür. Asetabular eklem kıkırdağı ve labrum, hipertrofik olarak izlenebilir. ${ }^{[20]}$

\section{Revaskülarizasyon ve Onarım Fazı}

Bu evrede, epifiz nekroz, revaskülarizasyon ve iyileşme alanlarının birlikte görülmesine bağlı olarak, konvansiyonel ve $+K M R^{\prime}$ 'de heterojen sinyal özellikleri ile izlenir. Revaskülarizasyon, damarların rekanalize olması ya da neovaskülarizasyon şeklinde ortaya çıkabilir. Revaskülarizasyon izlenen alanlarda, sıvıya duyarlı sekanslarda (T2-A ve STIR) artmış sinyal intensitesi ve $+K$ $M R$ görüntülerinde artmış kontrastlanma izlenir (Şekil 2). Revaskülarizayon görülen alanlar, avasküler nekroza gitmemiş alanlardan bile daha erken kontrastlanabilir. Femur başının lateral 1/3'lük kesiminin (lateral pillar) erken kontrastlanması, iyi prognoz ile ilişkili bulunmuştur. ${ }^{[16]}$ illerleyen dönemde, nekrotik kemik yerinde oluşan yeni kemik dokunun yağlı iliği, T1-A görüntülerde yüksek sinyal görülmesinden sorumludur. ${ }^{[21]}$ Revaskülarizasyon fazında, epifizde nekroza bağlı olarak eklem yüzeyinde yayvanlaşma (koksa plana) ve fragmantasyon izlenir (Şekil 3). Femur başının laterale subluksasyonu (Şekil 4) ve asetabulum tarafindan kapsanmasında azalmanın, kıkırdak doku kalınlığında artma, eklem içi sıvısının artışı ve sinoviyal kalınlaşmaya bağlı olduğu değerlendirilmektedir. ${ }^{[3]}$ Büyüme plağında düzensizlik, anormal transfizyel damarlara bağlı fizis hattında anormal kontrast tutulumu, fiziyel bar (kemik köprüleşme), epifizde kistik değişiklikler ve koksa magna deformitesi, görülebilen diğer bulgulardır.

Revaskülarizasyon ve onarım fazında, metafizde de değişiklikler meydana gelmektedir. Direkt grafide metafizyel radyolusensiler ya da kistler şeklinde görülen alanlar, MR görüntülerinde komşu fizis hattına benzer sinyal özellikleri ile izlenmekte ve bu görünümü ile ektopik fiziyel kıkırdağı ya da granülasyon dokusunu düşündürmektedir. DAG'de etkilenen tarafta artmış diffüzite görülür. Genç olgularda bu evrelerde, femoroasetabular sıkışmanın, labral yırtıkların ve kıkırdak defektlerinin gösterilmesinde MRA yararlıdır. 


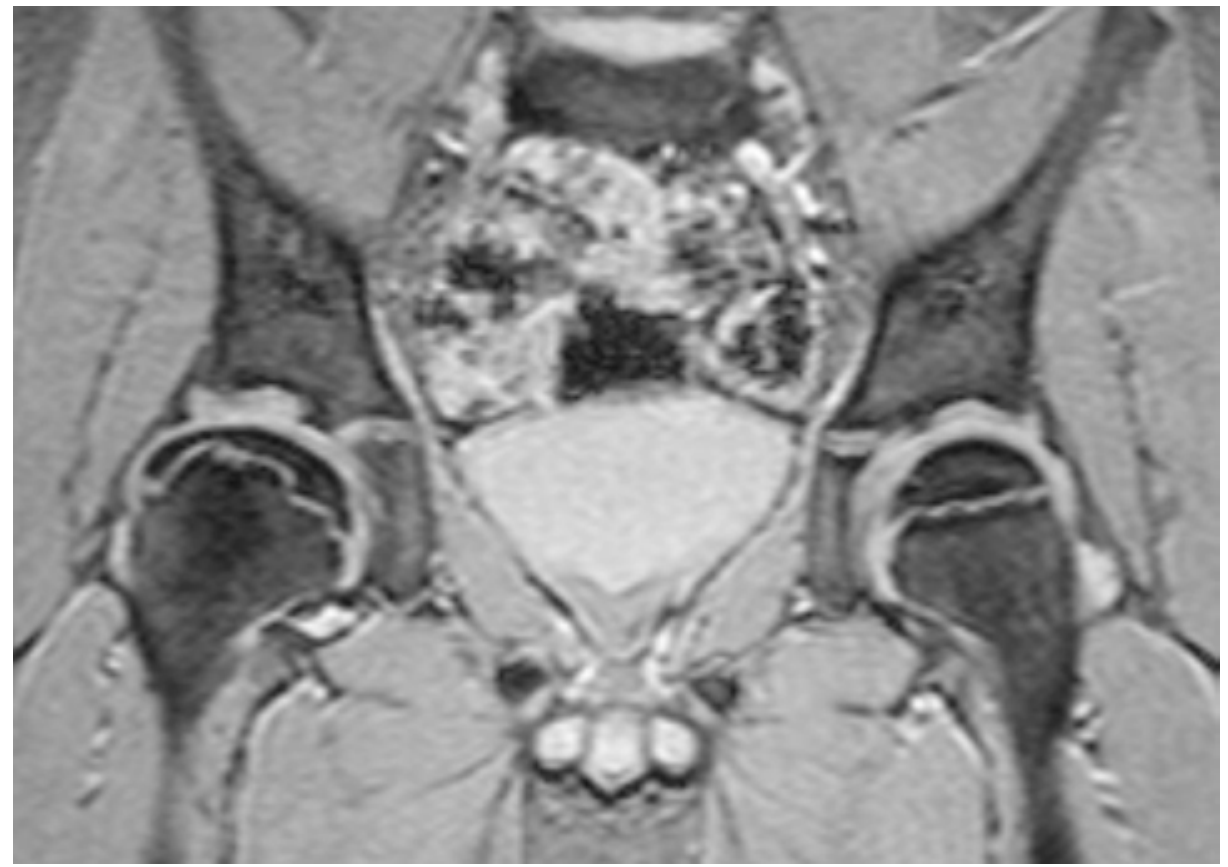

Şekil 3. Koronal GRE T2-A görüntüde; sağda asetabulum sığ olduğu haliyle izlenmektedir. Ayrıca, sağda koksa plana (femur başında yayvanlaşma) ve koksa brava (normalden kısa femur boynu) deformiteleri de tabloya eşlik etmektedir.
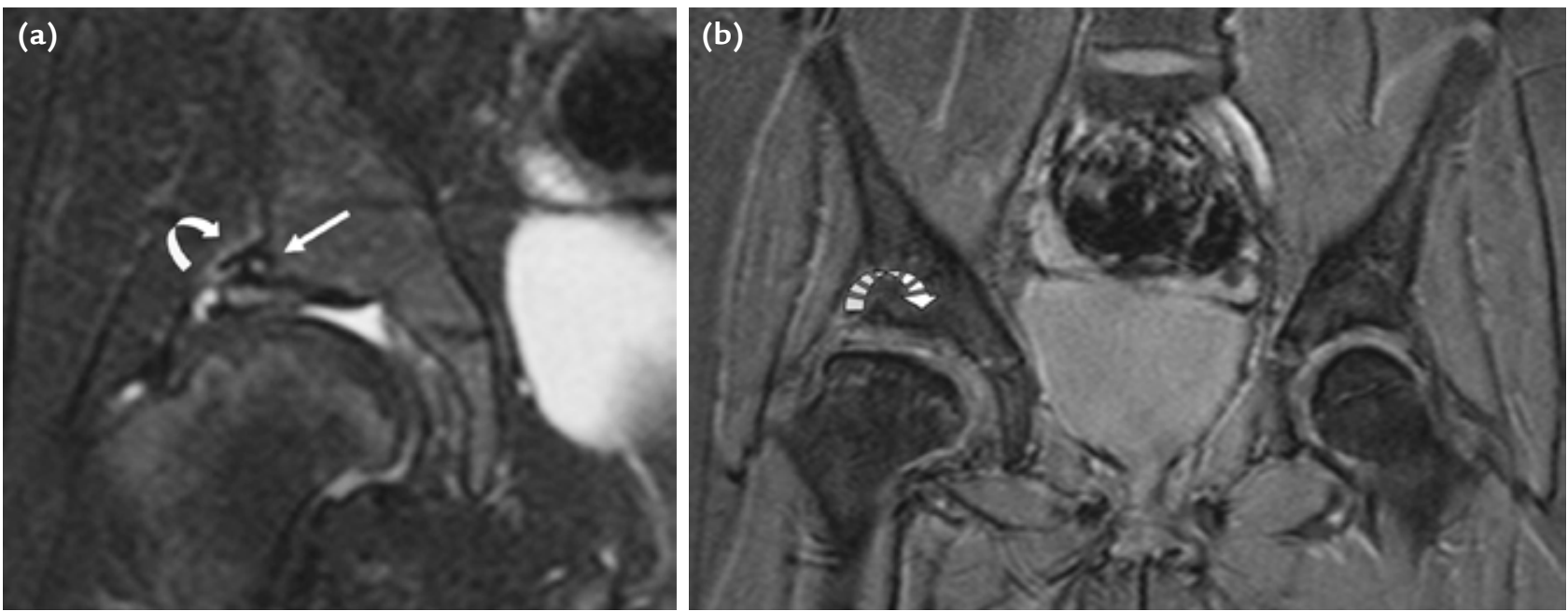

Şekil 4. a, b. Koronal yağ baskılı T2-A (a) ve GRE T2-A (b) görüntülerde; sağda sığ olan asetabulumda subkondral yerleşimde kistik değişiklik (ok) ve osteofitik sivrilme (eğri ok) vardır. Labrum kalın, femur başı ise laterale doğru sublukse olduğu haliyle izlenmektedir. Asetabular kıkırdağın kalınlığına dikkat ediniz (kesintili ĕgri ok).

\section{Prognoz}

Olguların \%50'si, belirgin fonksiyonel bozukluk oluşturmaksızın spontan olarak iyileşir. Etkilenen kalçaların bir bölümü ise hayatın ileri dönemlerinde ağrılı hale gelmekte ve bu olguların bazılarında artroplasti gerekliliği ortaya çıkmaktadır. Prematür dejenerasyon (sekonder osteoartrit), iyileşmiş LCP olgularında en sık rastlanan uzun dönem komplikasyondur. Bazı bulgular, kalça ekleminin erken dejenerasyonu, dolayısı ile kötü prognozla ilişkili olarak gösterilmektedir. Tanı esnasında kemik yaşı büyük olan olgular ve altı yaşından büyük tanı alan olgularda prognoz kötüdür. ${ }^{[22]} \mathrm{MR}$ görüntülerde; epifizde (özellikle lateral pillar kesiminde) tutulumun yaygınlığı, transfizyel neovaskülarizasyon, metafizyel sinyal değişiklikleri ve fiziyel bar varlığı kötü prognoza işaret eder (Şekil 5). 

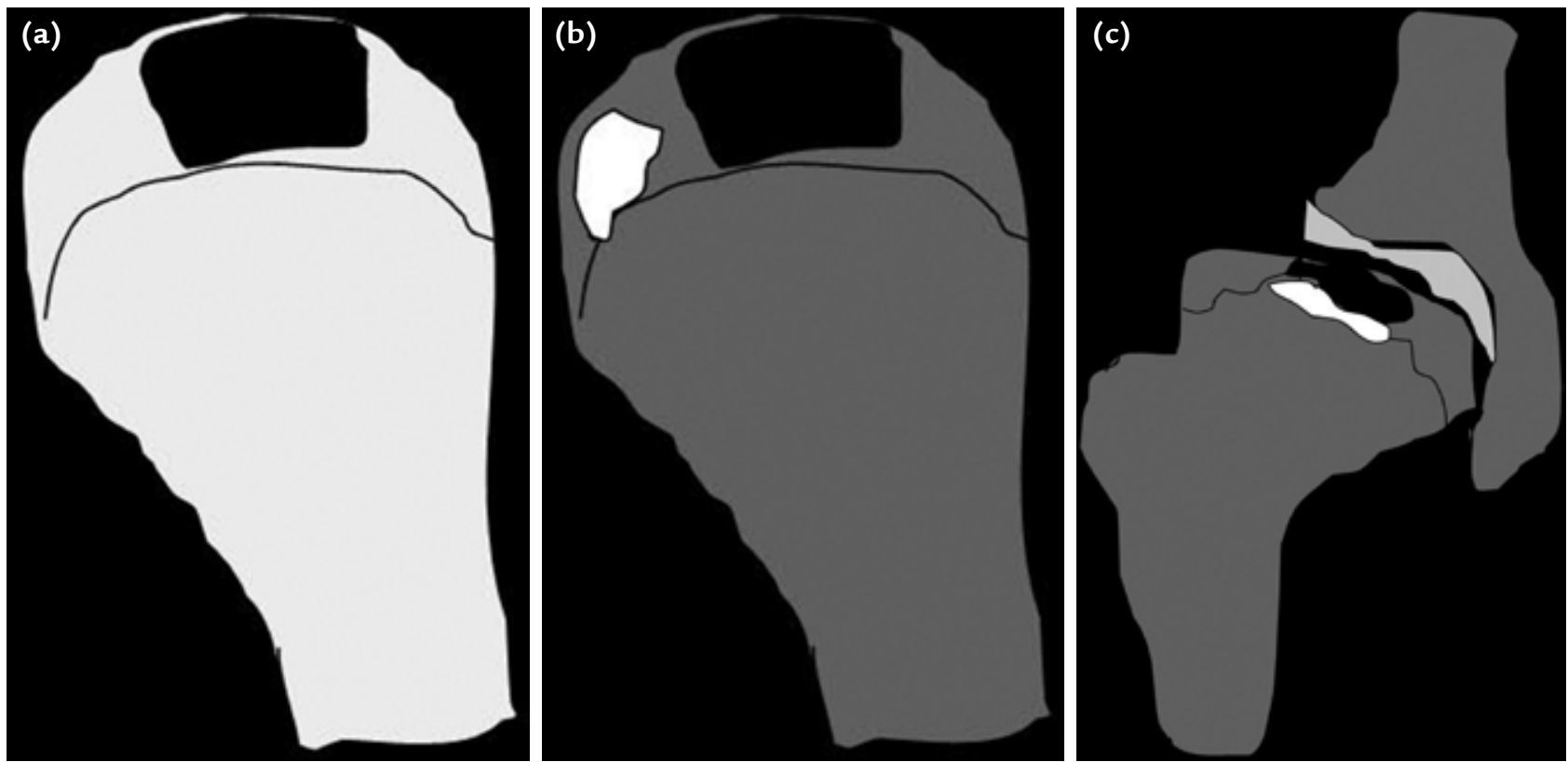

Şekil 5. a-c. Çizimlerle bazı MR bulgularına bakılırsa; sagittal femur çiziminde T1-A'da femoral ossifik nükleusta nekroz (santralde, beyaz tonunda izlenmesi gereken epifiz ortasında, siyah tonunda görülmekte) (a), sagittal femur çiziminde +K yağ baskılı T1A'da femoral ossifik nükleusta nekroz ile anteriorda görülen parlama neovaskülarizasyon ve granülasyona işaret etmekte. Epifizin posterior kesiminin kontrastlanmasının femurun diğer kesimlerine göre aynı tonda betimlenmesi, bu kesimin kanlanmasının korunduğuna işaret etmektedir (b). Koronal kalça eklemi çiziminde +K yağ baskılı T1-A'da femoral ossifik nükleusta nekroz ile hemen komşuluğunda görülen parlama, neovaskülarizasyon ve granülasyona işaret etmektedir. Kısa femur boynu, geniş başı ile hafif lateralizasyonu, büyük labrum ve kalın asetabular kıkırdak çizilmiştir (c).

\section{SONUÇ}

MR görüntüleme; çeşitli planlarda görüntülemeye elverişli olması, ileri MR görüntüleme yöntemlerinin desteği ve iyonizan radyasyon içermemesi nedeniyle, LCP hastalığının değerlendirmesi ve olguların (cerrahi / cerrahi olmayan) yönetiminde etkili bir görüntüleme yöntemidir (özet algoritma). Ayrıca, kontrast madde verilerek yapılan perfüzyon MR inceleme ile, proksimal femoral epifizin vaskülarizasyonundaki bozukluk erken dönemde tespit edilebilmektedir. MR görüntüleme, LCP hastalığının erken döneminde ya da LCP şüphesi durumunda, kalça ağrısının LCP haricindeki diğer nedenlerini ortaya koyarak tanıya katkıda bulunabilmektedir.

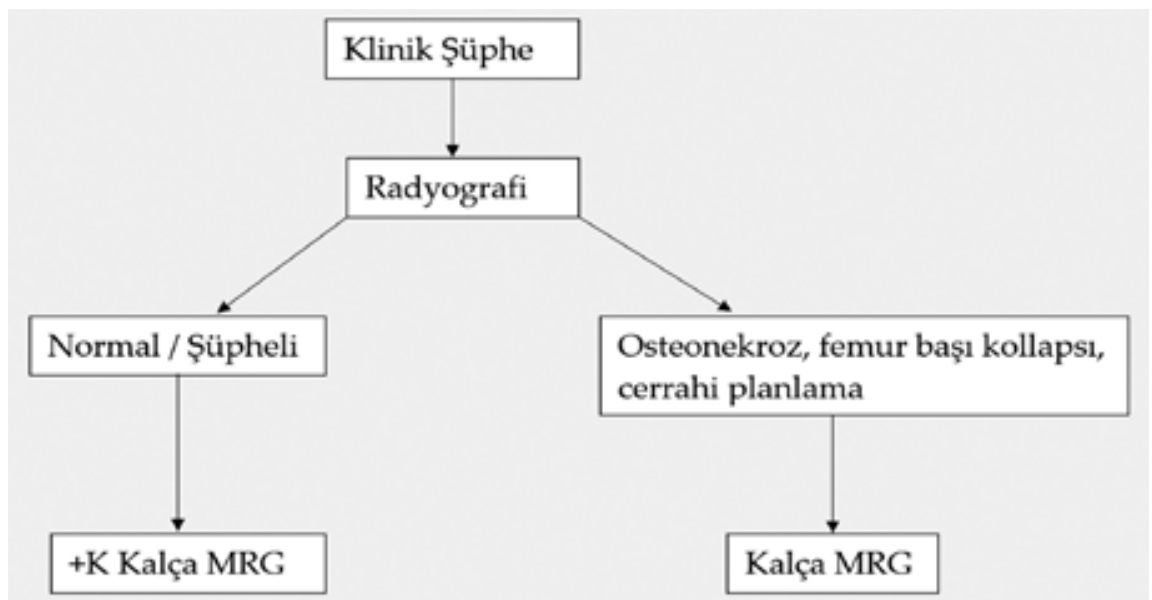

Şekil 6. Özet algoritma. ${ }^{[1]}$ (Murphey MD, et al. ACR Appropriateness Criteria Osteonecrosis of the Hip. J Am Coll Radiol 2016;13(2):147-55'ten çıkarım yapılarak uyarlanmıştır) 


\section{KAYNAKLAR}

1. Murphey MD, Roberts CC, Bencardino JT, Appel M, Arnold E, Chang EY, Dempsey ME, Fox MG, Fries IB, Greenspan BS, Hochman MG, Jacobson JA, Mintz DN, Newman JS, Rosenberg ZS, Rubin DA, Small KM, Weissman BN. ACR Appropriateness Criteria Osteonecrosis of the Hip. J Am Coll Radiol 2016;13(2):147-55. Crossref

2. Herring JA, Williams JJ, Neustadt JN, Early JS. Evolution of femoral head deformity during the healing phase of LeggCalvé-Perthes disease. J Pediatr Orthop 1993;13(1):41-5.

3. Jaramillo D, Galen TA, Winalski CS, DiCanzio J, Zurakowski D, Mulkern RV, McDougall PA, Villegas-Medina OL, Jolesz FA, Kasser JR. Legg-Calvé-Perthes disease: MR imaging evaluation during manual positioning of the hip comparison with conventional arthrography 1. Radiology 1999;212(2):519-25.

4. Dillman JR, Hernandez RJ. MRI of Legg-Calvé-Perthes disease. AJR Am J Roentgenol 2009;193(5):1394-407. Crossref

5. Sankar WN, Thomas S, Castañeda P, Hong T, Shore BJ, Kim HK; Study Conducted by the International Perthes Study Group. Feasibility and safety of perfusion MRI for LeggCalvé-Perthes disease. J Pediatr Orthop 2014;34(7):679-82. Crossref

6. Ha AS, Wells L, Jaramillo D. Importance of sagittal MR imaging in nontraumatic femoral head osteonecrosis in children. Pediatr Radiol 2008;38(11):1195-200. Crossref

7. Mahnken A, Staatz G, Ihme N, Günther RW. MR signal intensity characteristics in Legg-Calvé-Perthes disease. Value of fat-suppressed (STIR) images and contrast-enhanced T1weighted images. Acta Radiol 2002;43(3):329-35.

8. Chaudhry S, Phillips D, Feldman D. Legg-Calvé-Perthes Disease: an overview with recent literature. Bull Hosp Jt Dis (2013) 2014;72(1):18-27.

9. Maranho DAC, Nogueira-Barbosa MH, Zamarioli A, Volpon JB. MRI abnormalities of the acetabular labrum and articular cartilage are common in healed Legg-Calvé-Perthes disease with residual deformities of the hip. J Bone Joint Surg Am 2013;95(3):256-65. Crossref

10. Tsao AK, Dias LS, Conway JJ, Straka P. The prognostic value and significance of serial bone scintigraphy in Legg-CalvéPerthes disease. J Pediatr Orthop 1997;17(2):230-9.

11. Li X, Qi J, Xia L, Li H, Hu J, Yu C, Pen W, Guan J, Hu D. Diffusion MRI in ischemic epiphysis of the femoral head: an experimental study. J Magn Reson Imaging 2008;28(2):4717. Crossref
12. Baunin C, Sanmartin-Viron D, Accadbled F, Sans N, Vial J, Labarre D, Domenech C, Sales de Gauzy J. Prognosis value of early diffusion MRI in Legg Perthes Calvé disease. Orthop Traumatol Surg Res 2014;100(3):317-21. Crossref

13. Boutault JR, Baunin C, Bérard E, Vial J, Labarre D, Domenech C, Sales de Gauzy J, Sans N. Diffusion MRI of the neck of the femur in Legg-Calvé-Perthes disease: a preliminary study. Diagn Interv Imaging 2013;94(1):78-83. Crossref

14. Herring JA, Neustadt JB, Williams JJ, Early JS, Browne RH. The lateral pillar classification of Legg-Calvé-Perthes disease. J Pediatr Orthop 1992;12(2):143-50.

15. Kim HK, Wiesman KD, Kulkarni V, Burgess J, Chen E, Brabham C, Ikram H, Du J, Lu A, Kulkarni AV, Dempsey M, Herring JA. Perfusion MRI in Early Stage of Legg-Calvé-Perthes Disease to Predict Lateral Pillar Involvement. J Bone Joint Surg Am 2014;96(14):1152-60.

16. Lamer S, Dorgeret S, Khairouni A, Mazda K, Brillet PY, Bacheville E, Bloch J, Penneçot GF, Hassan M, Sebag $\mathrm{GH}$. Femoral head vascularisation in Legg-Calvé-Perthes disease: comparison of dynamic gadolinium-enhanced subtraction MRI with bone scintigraphy. Pediatr Radiol 2002;32(8):580-5.

17. Kim HK, Kaste S, Dempsey M, Wilkes D. A comparison of noncontrast and contrast-enhanced MRI in the initial stage of Legg-Calvé-Perthes disease. Pediatr Radiol 2013;43(9):116673. Crossref

18. Du J, Lu A, Dempsey M, Herring JA, Kim HK. MR perfusion index as a quantitative method of evaluating epiphyseal perfusion in Legg-Calvé-Perthes disease and correlation with short-term radiographic outcome: a preliminary study. J Pediatr Orthop 2013;33(7):707-13. Crossref

19. Bos CF, Bloem JL, Bloem RM. Sequential magnetic resonance imaging in Perthes' disease. J Bone Joint Surg $\mathrm{Br}$ 1991;73(2):219-24.

20. Rush BH, Bramson RT, Ogden JA. Legg-Calvé-Perthes disease: detection of cartilaginous and synovial change with MR imaging. Radiology 1988;167(2):473-6.

21. Lahdes-Vasama T, Lamminen A, Merikanto J, Marttinen E. The value of MRI in early Perthes' disease: an MRI study with a 2-year follow-up. Pediatr Radiol 1997;27(6):517-22.

22. Roy DR. Current concepts in Legg-Calvé-Perthes disease. Pediatr Ann 1999;28(12):748-52. 